\title{
Winterization of Vegetable Oil Blends for Biodiesel Fuels and Correlation Based on Initial Saturated Fatty Acid Constituents
}

Heng Zhong, ${ }^{\dagger}$ Masaru Watanabe, ${ }^{*} \dagger,+$ Heiji Enomoto, ${ }^{\ddagger}$ Fangming Jin, ${ }^{\ddagger}{ }^{\ddagger}$ Atsushi Kishita, ${ }^{\ddagger}$ Taku Michael Aida, ${ }^{\dagger}$ and Richard Lee Smith, Jr. ${ }^{\dagger, \ddagger}$

${ }^{\dagger}$ Research Center of Supercritical Fluid Technology, Tohoku University, Aoba-ku, Sendai 980-8579, Japan

${ }^{*}$ Graduate School of Environmental Studies, Tohoku University, Aoba-ku, Sendai 980-8579, Japan

${ }^{\S}$ School of Environmental Science and Engineering, Shanghai Jiao Tong University, 800 Dongchuan Road, Shanghai 200240, China

*Corresponding Author: Masaru Watanabe

Tel/Fax: +81-22-795-5864

E-mail: meijin@scf.che.tohoku.ac.jp 


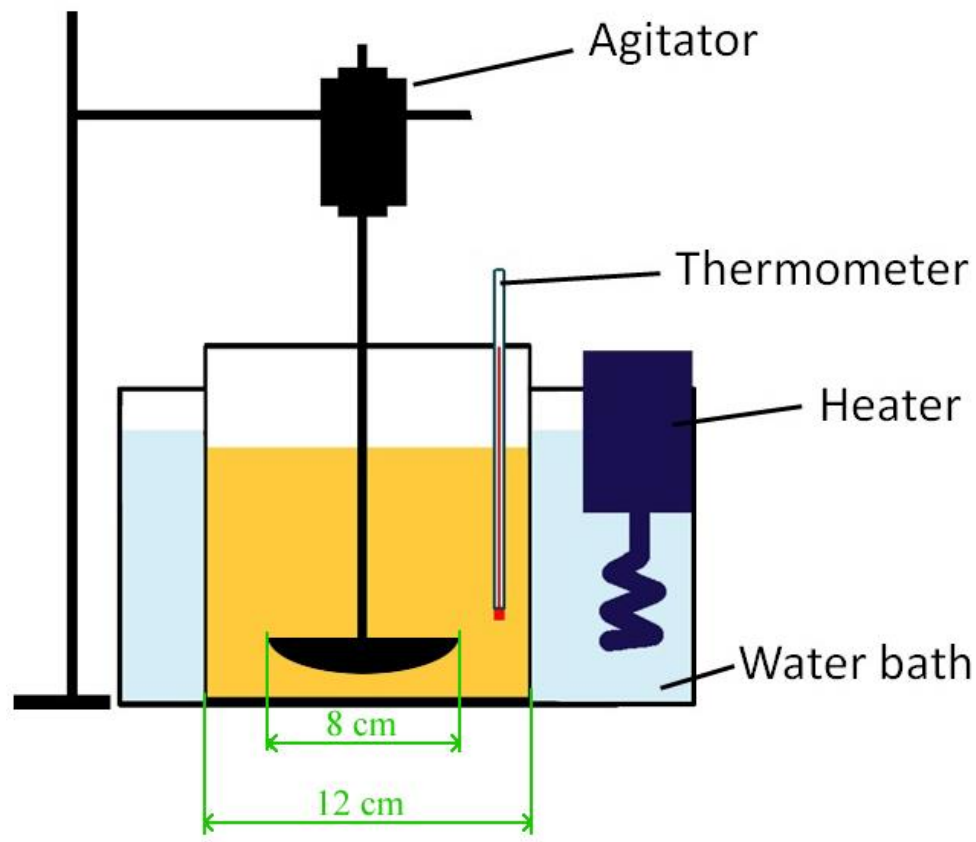

Figure S1. Schematic of the transesterification reaction setup for preparing biodiesels from oil blends. 

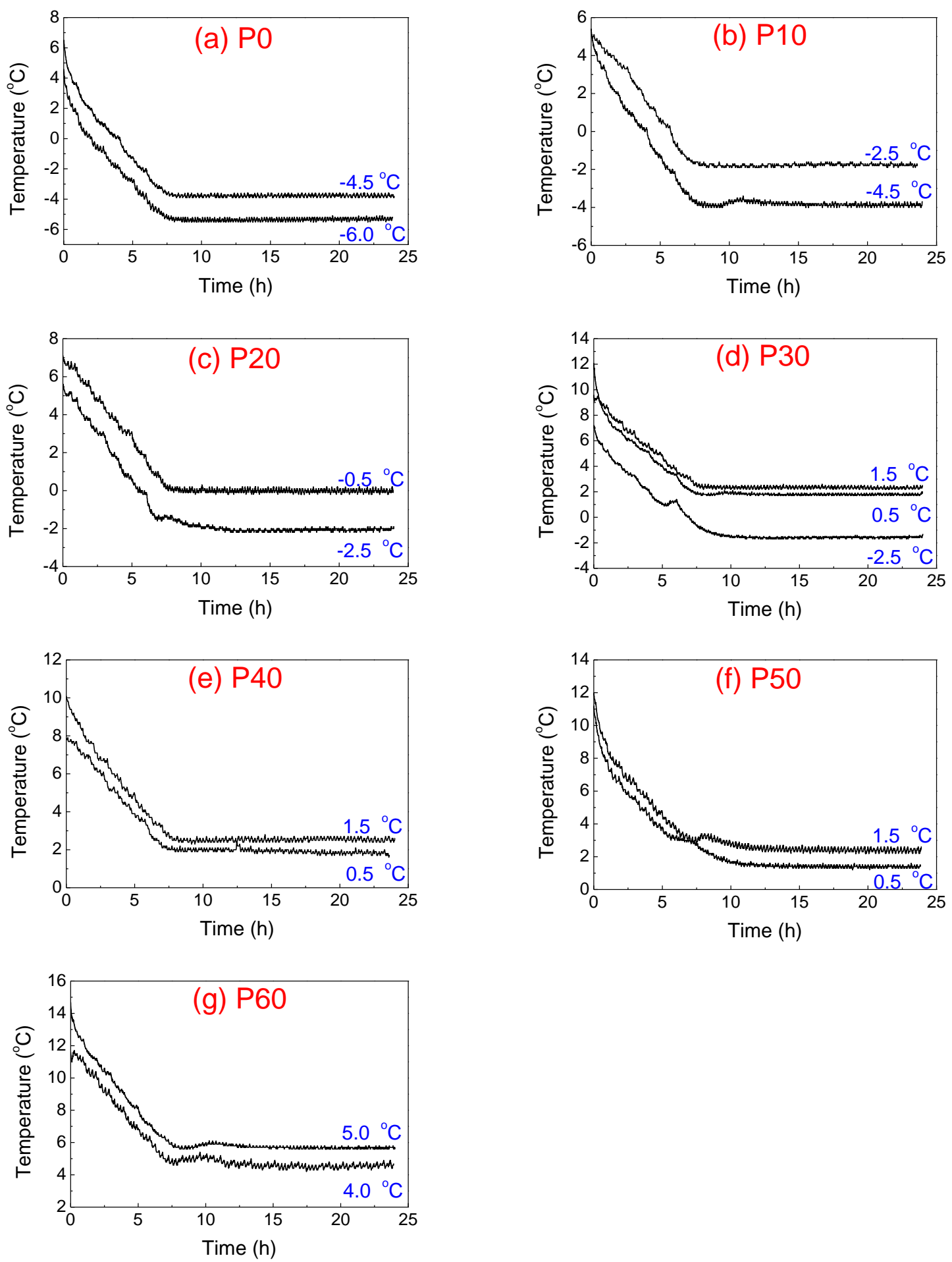

Figure S2. Temperature profiles of biodiesels during the winterization experiment (blue temperature numbers in the figures stand for the set-point of the winterization temperature; each line represents an independent experiment). 


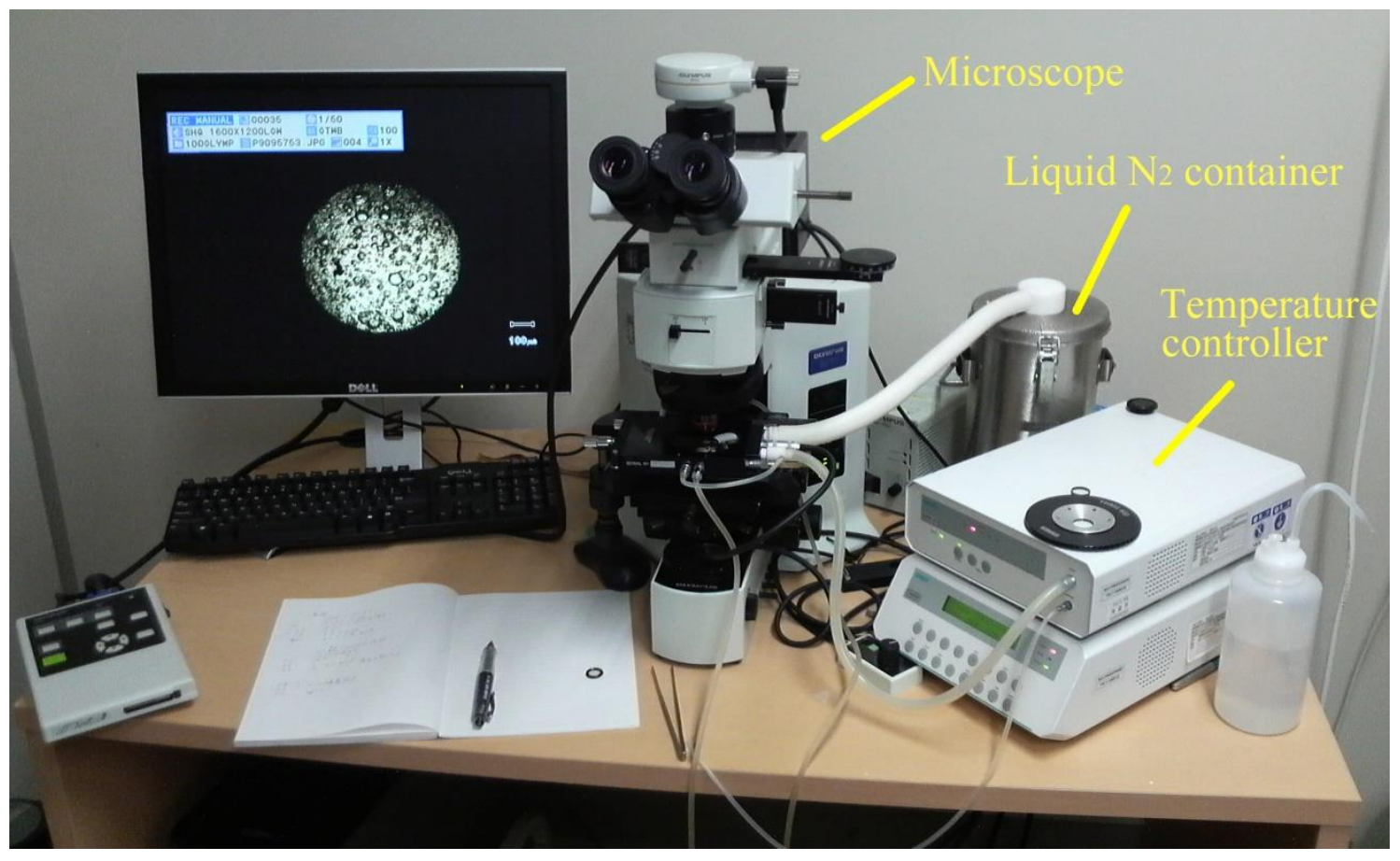

Figure S3. Temperature controllable microscope system. 


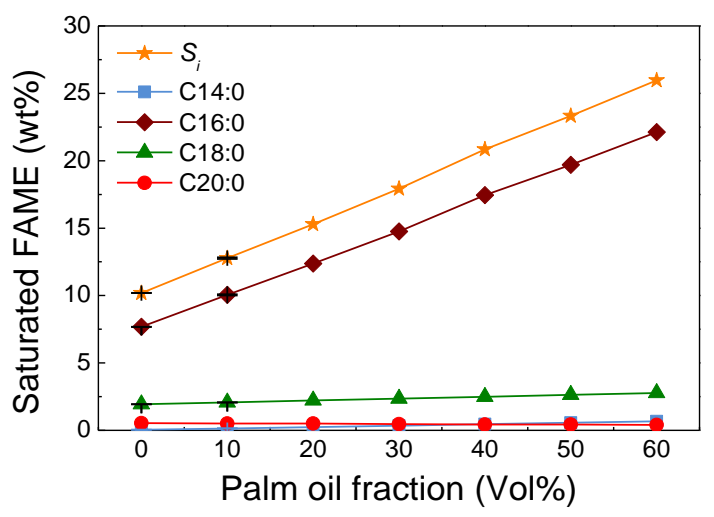

(a)

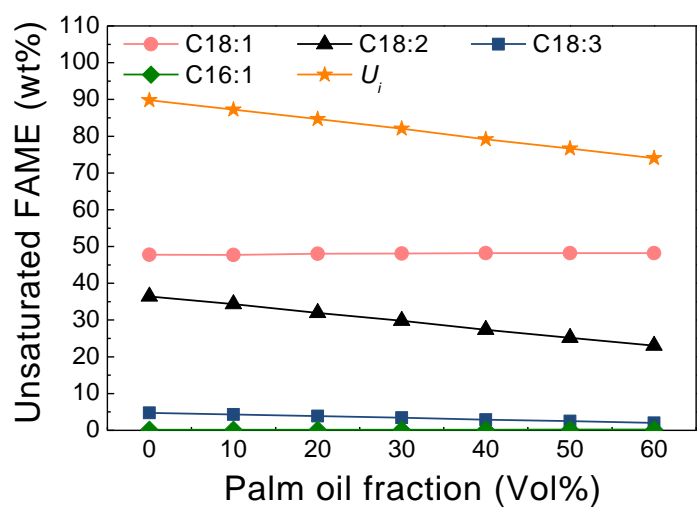

(b)

Figure S4. Saturated (a) and unsaturated (b) FAME content for biodiesels prepared from oil blends with various volumetric percentages of palm, canola and corn oils. See Table 2 (main text) for oil blend volumetric percentages. 
Table S1. Densities and viscosities of the oils used in this research measured at $25^{\circ} \mathrm{C}$ at $0.1 \mathrm{MPa}$.

\begin{tabular}{ccc}
\hline & $\begin{array}{c}\text { Density } \\
\left(\mathrm{g} / \mathrm{cm}^{3}\right)\end{array}$ & $\begin{array}{c}\text { Viscosity } \\
(\mathrm{mPa} \cdot \mathrm{s})\end{array}$ \\
\hline Palm oil & 0.911 & 71.67 \\
Canola oil & 0.914 & 57.65 \\
Corn oil & 0.916 & 51.51 \\
\hline
\end{tabular}


Table S2 Saturated FAME composition and reduction ratios of P30 after winterizing at different temperatures.

\begin{tabular}{|c|c|c|c|c|c|c|c|c|c|c|}
\hline \multirow{2}{*}{$\begin{array}{c}T_{w} \\
\left({ }^{\circ} \mathrm{C}\right)\end{array}$} & \multicolumn{5}{|c|}{ Saturated FAME composition (wt $\%$ ) } & \multicolumn{5}{|c|}{ Saturated FAME reduction ratios ${ }^{\mathrm{a}}(\mathrm{wt} \%)$} \\
\hline & C14:0 & C16:0 & C18:0 & C20:0 & Total $^{\mathrm{b}}$ & C14:0 & C16:0 & C18:0 & C20:0 & Overall \\
\hline Initial $^{\mathrm{c}}$ & 0.345 & 14.762 & 2.352 & 0.467 & 17.926 & - & - & - & - & - \\
\hline 2.3 & 0.350 & 14.482 & 2.319 & 0.465 & 17.616 & -1.449 & 1.897 & 1.403 & 0.428 & 1.729 \\
\hline 1.8 & 0.351 & 13.687 & 2.243 & 0.429 & 16.710 & -1.739 & 7.282 & 4.634 & 8.137 & 6.783 \\
\hline 0.4 & 0.352 & 11.440 & 1.992 & 0.369 & 14.153 & -2.029 & 22.504 & 15.306 & 20.985 & 21.048 \\
\hline-1.5 & 0.357 & 9.203 & 1.694 & 0.303 & 11.557 & -3.478 & 37.657 & 27.976 & 35.118 & 35.529 \\
\hline
\end{tabular}

${ }^{a}$ Reduction ratios calculated from Eq. (1) in the main text; negative entries infer that the reduction ratio increases which is due to the small amount of initial material and the uncertainty in the chromatographic analyses.

${ }^{\mathrm{b}}$ Total: sum of C14:0, C16:0, C18:0, C20:0.

${ }^{\mathrm{c}}$ Initial composition before winterization. 